\title{
Financial Development and Natural Resources Dynamics in Saudi Arabia: Visiting 'Resource Curse Hypothesis' by NARDL and Wavelet-Based Quantile-on-Quantile Approach
}

\author{
Imran Sharif Chaudhry $^{\text {a }}$, Muhammad Faheem ${ }^{b}$, Fatima Farooq ${ }^{c}$, Sajid Ali ${ }^{d}$ \\ ${ }^{a}$ Dean of Social Sciences and Director, School of Economics Bahauddin Zakariya University, Multan, \\ Pakistan \\ Email: imran@bzu.edu.pk \\ ${ }^{\mathrm{b}}$ Assistant Professor, School of Economics Bahauddin Zakariya University, Multan, Pakistan; \\ Email: faheem@bzu.edu.pk \\ ${ }^{c}$ Associate Professor School of Economics Bahauddin Zakariya University, Multan Pakistan \\ Email: fatimafarooq@bzu.edu.pk \\ ${ }^{\mathrm{d}}$ PhD Scholar, School of Business and Economics, Universiti Putra, Malaysia \\ Email: sajidali1136@gmail.com
}

\begin{tabular}{|c|c|}
\hline ARTICLE DETAILS & ABSTRACT \\
\hline $\begin{array}{l}\text { History: } \\
\text { Accepted } 12 \text { March } 2021 \\
\text { Available Online March } 2021\end{array}$ & $\begin{array}{l}\text { This study analyses the impact of natural resource rent on financial } \\
\text { development to test the resource curse hypothesis in Saudi Arabia on } \\
\text { quarterly data span from 1985Q1 to 2017Q4. We employ two novel } \\
\text { methodologies at same time such as nonlinear autoregressive model }\end{array}$ \\
\hline $\begin{array}{l}\text { Keywords: } \\
\text { Natural Resource Rent, Financial } \\
\text { Development, NARDL, Wavelet- } \\
\text { based Quantile-on-Quantile, } \\
\text { Saudi Arabia }\end{array}$ & $\begin{array}{l}\text { (NARDL) and Wavelet-based quantile-on-quantile estimation to check } \\
\text { the asymmetric behaviour of natural resource rent on financial } \\
\text { development. The findings of NARDL confirm the nonlinear behaviour of } \\
\text { natural resource rent with financial development. The results also show } \\
\text { real GDP, gross capital formation and institutional quality affect } \\
\text { financial development positively. The empirical results of Wavelet-based }\end{array}$ \\
\hline $\begin{array}{l}\text { JEL Classification: } \\
A_{19}, C_{5} 8, \text { Goo, Q34 }\end{array}$ & $\begin{array}{l}\text { quantile-on-quantile estimation method also reveal the heterogeneous } \\
\text { response of natural resource rent effect when decomposes into different } \\
\text { quantiles that become positive to negative. The results further explain }\end{array}$ \\
\hline DOI: & $\begin{array}{l}\text { that the natural resource rent has a positive effect in short-run, but it } \\
\text { exerts an adverse effect on financial development after attaining } \\
\text { stability. }\end{array}$ \\
\hline
\end{tabular}

(C) 2021 The authors. Published by SPCRD Global Publishing. This is an open access article under the Creative Commons Attribution-

NonCommercial 4.0

Corresponding author’s email address: imran@bzu.edu.pk

\section{Introduction}

The resource scarcity risk is always involved in resource and financial market. Natural resources are beneficial in the development and an asset of a country (Asif et al., 2020). Still, under certain conditions, natural resources create an exigent environment for development in the financial sector (Guan et al., 2020). The mostly highly resource-rich economies are facing the reduction in financial 


\section{Review of Economics and Development Studies, Vol. 7 (1) 2021, 101-117}

development level and empirically have shown in literature such as (Sachs and Warner, 2001; Hooshmand et al., 2013; Elbadawi and Soto, 2016; Zhang and Brouwer, 2020; Khan et al., 2020). The resource-rich countries financial sector may be flushed with liquidity from different sources like government tax receipts, companies (state or private owned) that are working in the resource sector. Therefore, it may expect in resource-rich economies more bank credits to household or firms and more developed financial markets. To understand the association of resource and financial development is much essential due to several reasons. Natural resources affect financial development, which influences long-run economic growth through a sound mechanism. It helps policymakers to address the resource curse through new advanced strategies and provides a further explanation on a different level of financial development.

Theoretically, the resource curse theory postulates about the reason of the economic failure of resource abundance countries, and empirically, it is proved in the majority of the studies (Sachs and Warner, 2001; Zhang et al., 2018). The studies explained several factors that cause resource curse hypothesis such as corruption, rent-seeking behaviour, lagged manufacturing sector investment and low level of institutional quality and commodity price shocks in resource-rich countries (Mlachila and Ouedraogo, 2019). Financial development is assumed to be a base for converting resource curse into resource blessing in the presence of high institutional quality, high trade and high quality of human capital (Rajan and Zingales, 2003). Existing studies shows the harmful connection of resources with financial development (Cordon and Neary, 1982; Zoega and Gylfason, 2001; Guan et al., 2020; Sun et al., 2020). On the other hand, there is a literature in the contradiction of these studies that shows the positive link (Balassa, 1980; Sachs and Warner, 1995; Auty, 2001; Shahbaz et al., 2018; Nawaz et al., 2019). Thus, our study gives policy guidelines for the achievement of financial development with effective natural resource utilization in an economy and also a lesson for the global world.

Oil rent is the major source to stimulate resource abundance economies growth through the mechanism of good governance (Niknamian, 2019). Saudi Arabia's fiscal revenue mostly covers oil revenue, which consists of $80 \%$ and non-oil revenue, only $20 \%$ of the total revenue from 1970 to 2018 (SAMA, 2018). There is limited progress toward diversification, and still, Saudi Arabia heavily depends on oil exports in merchandise exports that accounted for $84 \%$ between 2005 to 2018 (Al-Torkistani et al., 2016; SAMA, 2018). However, Saudi Arabia launched a strategic plan 'Vision 2030', in April 2016, to concentrate on other sectors rather than oil sector, sustainable and balanced the economy ended the next decade and a half (Bah and Saari, 2020). Furthermore, the Saudi Arabia government gave priority to the financial sector in the implementation of the fourth development plan (Samargandi et al., 2014). And Saudi Arabia has a comprehensive financial infrastructure, Islamic bank accounts for $49 \%$ of the total banking sector (Islamic Financial Services Board, 2016). However, there is a need to give more focus on the financial sector on a priority basis.

Considerable research has been done in the abovementioned, but still, there is a need to test the resource curse theory in Saudi Arabia, which highly resources abundance country. Therefore, the contribution of the study in several ways: (i) This paper explores the resource curse hypothesis validation in Saudi Arabia, and the outcome of this study helps the policymakers and government officials. (ii), The existing studies used the traditional econometric methods to estimate the relation of resource abundance and financial development, but this study uses a recently developed two estimation methods at the same time such as nonlinear autoregressive method and Wavelet-based Quantile-onQuantile estimation method that incorporating issues of time-frequency and nonlinearities. Due to several factors, this method attracts and appeals to the researchers over traditional methods like gives more efficient estimators, outlier free and more robust and avoids heteroscedasticity. (ii) Furthermore, 


\section{Review of Economics and Development Studies, Vol. 7 (1) 2021, 101-117}

the study uses quarterly data to prove the resource curse hypothesis over 1985Q1-2017Q4 because this longitudinal data gives the meaningful outcome of two variables in the analysis.

The study is proceeding as following: Section-ii outlines a succinct theoretical and empirical literature about resource abundance-financial development. Section-iii gives adopt methodology and data, and section-iv reports the discussion of the results. Section-v evaluates the policy implication and conclusion.

\section{Literature Review}

The existing literature initially rigorous natural resources as a blessing that is the positive association of natural resources with growth until the 1980s. However, that may convert into a curse as chances of unfavourable political and economic scenarios may increase in resource abundance countries. Then it was challenged in the early 1990s, and Sachs and Warner (1995) gave the concept of the "Resource Curse Hypothesis" that showed the negative association. This is because resourcedependent economies increase natural resources export rather than the production of goods by these resources, and some other factors are responsible for negative economic growth like unstable political and financial institutions, dependence on rent, Dutch disease, failure in education (Auty and Warhurst, 1993; Sachs and Warner, 2001; Van der Ploeg and Venables, 2009). The resource blessing to resource curse is not true for all countries because countries convert into prosperity due to natural resource and financial development relation with the strong institutional quality background. However, the literature shows an unclear picture to policymakers about this relationship that natural resource is the source of stimulation of economic growth and especially financial growth. The plethora of existing studies show the overall negative tie of natural resources with financial development, especially in developing economies, but this relation is positive in high-income economies. For example, Shahbaz et al. (2018) revealed a positive involvement of natural resources and financial development by the argument that enhances due to the diffusion of knowledge and the incessant growth in the United States. Nawaz et al. (2019) also support the positive effect on a natural resource on financial development. Furthermore, other findings support in positive effect and suggest that more credit available to households and firms in resource-rich economies that contribute to financial development (Bhattacharyya and Hodler 2014).

The other side of the coin in existing literature shows the contradicting results in different resource-rich countries over a different time period. For example, Zoega and Gylfason (2001) analyzed the resource abundance and financial development relation by employing a seemingly unrelated regression (SUR) over 1965-1998 in 85 economies and found a negative association. Yuxiang and Chen (2011) explore the association of resource and financial development by employing the GMM method over 1996 to 2006. The study concludes that the areas with highly depend on the natural resource are slower in financial development as compared to poor natural resources areas. Sun et al. (2020) analyze in emerging seven (E7) countries about the natural resource and financial development link over 19902017. The study concludes that the negative influence of natural resource rent on financial development. In support of this argument, another study explained the connection of resources with other control variables with financial development over 1987-2017 and confirms the resource curse hypothesis for China (Khan et al., 2020). Similarly, Guan et al. (2020) revealed natural resources impact on financial development within multiframework over 1971-20-17 in China and found natural resources and financial development adversely affect. Asif et al. (2020) study findings are similar in favour of resource curse hypothesis that is a negative alliance of natural resource with financial development over 1987-2017 in China. The study of Shahbaz et al. (2019) explore resource dependence and resource abundance effect on growth in the presence of financial development variables with some others and revealed that resource abundance encourages growth while natural resource dependence slowdown it. Hooshmand et al. (2013) explore the outcome of natural resource rent for oil-dependent 
Review of Economics and Development Studies, Vol. 7 (1) 2021, 101-117

economies in the presence of institutions on financial development. The finding reveals that natural resource deteriorates the financial development process that ultimately declines the growth from 2002 to 2010. Other studies like Dwumfour and Ntow-Gyamfi (2018) explored the unclear effect of a natural resource on financial development in 38 African economies over 2000-2012.

Some other factors trigger financial development like economic growth, gross capital formation and institutional quality. The economic growth of an economy is considered a crucial element or determinant of financial development. The study of Song et al. (2020) documents the relationship of economic growth, corruption and financial development in developing countries by employing panel data techniques. The finding supports that economic growth affects positively while corruption associated negatively from the period of 2002 to 2016. Ghirmay (2004) explored the relation of economic growth with financial development in African economies by employing Vector autoregression and found that economic growth trigger financial development. Erdoğan et al. (2020) explored the cointegration between a natural resource, economic growth and financial development for the period of 1996-2016 in selected Next-11 countries and findings supports the long-run association between a natural resource, economic growth and financial development. Omri et al. (2015) findings are in support of the same result in MENA countries. The role of capital formation is considered as one of the most important element that contributes in economic growth as well as financial development which is recently proved in literature in different countries and different regions (Khan et al., 2020; ). The study of Khan et al. (2020) explored the association of natural resource with the gross capital formation with other control variables for proving the resource curse hypothesis in Pakistan. The study employs ARDL estimation to test the theory from 1975 to 2017 and found gross capital formation contributed positively to financial development. Similarly, in OECD economies, the study of Zaidi et al. (2019) results is in favor of the association of natural resource, globalization, human capital and financial development.

However, the literature on resource and financial development tends to be inconsistent, and there is a need to investigate more on this issue in most resource dependence country like Saudi Arabia by hypothesizing effect of a natural resource on financial development or testing the resource curse phenomenon. And the outcome of this study will helpful for other resource-rich countries around the globe.

\section{Material and Methods}

This paper uses financial development as the dependent variable and total natural resource rent as the main independent variable in Saudi Arabia. The study also uses some control variables like real GDP, gross capital formation and institutional quality. The data is sourced from WDI for mostly variables and from ICRG for institutional quality data, and data range is 1975Q1 to 2017Q4. For the transformation of the data, the quadratic match sum method is employed that can handle the complications of transforming of data (Cheng et al., 2012; Shahbaz et al., 2018).

\subsection{Nonlinear Autoregressive Model (NARDL)}

Financial development is determined by natural resource, economic growth, gross capital formation and institutional quality.

$$
\begin{gathered}
\boldsymbol{F D}=\boldsymbol{f}(\boldsymbol{N R R}, \boldsymbol{G D P}, \boldsymbol{G C F}, \boldsymbol{I N Q}) \\
F D_{t}=\beta_{1}+\beta_{2} N R R_{t}+\beta_{3} G D P_{t}+\beta_{4} G C F_{t}+\beta_{5} I N Q_{t}+\mu_{t}
\end{gathered}
$$


In the above econometric model, the coefficients $\beta_{2}, \beta_{3}, \beta_{4}$, and $\beta_{5}$ are the elasticities of financial development concerning the natural resource rent, gross domestic product, gross capital formation and institutional quality.

To estimate the above model, firstly we formulate this model in the ARDL bounds approach:

$$
\begin{aligned}
& \Delta F D_{t}=\alpha_{0}+\sum_{i=1}^{l} a_{1 i} \Delta F D_{t-1}+\sum_{i=0}^{p} \alpha_{2 i} \Delta N R R_{t-i}+\sum_{i=0}^{q} \alpha_{3 i} \Delta G D P_{t-i}+\sum_{i=0}^{r} \alpha_{4 i} \Delta G C F_{t-i}+\sum_{i=0}^{s} \alpha_{5 i} \Delta I N Q_{t-i}+ \\
& +\beta_{1} F D_{t-1}+\beta_{2} N R R_{t-1}+\beta_{3} G D P_{t-1}+\beta_{4} G C F_{t-1}+\beta_{5} I N Q_{t-1}+\mu_{t}
\end{aligned}
$$

The following equation expresses the estimation of unrestricted error correction model (ECM):

$$
\begin{aligned}
& \Delta F D_{t}=\alpha_{0}+\sum_{i=1}^{l} a_{1} \Delta F D_{t-i}+\sum_{i=0}^{p} \alpha_{2} \Delta N R R_{t-i}+\sum_{i=0}^{q} \alpha_{3} \Delta G D P_{t-i}+\sum_{i=0}^{r} \alpha_{4} \Delta G C F_{t-i}+\sum_{i=0}^{s} \alpha_{5} \Delta I N Q_{t-i} \\
& +\lambda E C T-1+v t_{t}
\end{aligned}
$$

The speed of adjustment parameter denoted by $\lambda$ and ECT denotes the residuals from the estimated model.

Our main purpose is to check the asymmetric or nonlinear behaviour of natural resource rent with financial development and model can be formulated by breaking the natural resource rent variable into positive and negative parts in the formulation of Shin, Yu and Greenwood-Nimmo (2014) as follows:

$$
\begin{aligned}
& \Delta F D_{t}=\alpha_{0}+\sum_{i=1}^{l} a_{1 i} \Delta F D_{t-1}+\sum_{i=0}^{p 1} \alpha^{+}{ }_{2 i} \Delta N R R_{t-i}^{+}+\sum_{i=0}^{p 2} \alpha^{-}{ }_{2 i} \Delta N R R^{-}{ }_{t-i}+\sum_{i=0}^{q} \alpha_{3 i} \Delta G D P_{t-i}+\sum_{i=0}^{r} \alpha_{4 i} \Delta G C F_{t-i}+\sum_{i=0}^{s} \alpha_{5 i} \Delta I N Q_{t-i}+ \\
& +\beta_{1} F D_{t-1}+\beta_{2}^{+} N R R_{t-1}^{+}+\beta^{-}{ }_{2} N R R_{t-1}^{-}+\beta_{3} G D P_{t-1}+\beta_{4} G C F_{t-1}+\beta_{5} I N Q_{t-1}+\mu_{t}
\end{aligned}
$$

$\beta_{2}{ }^{+}$and $\beta_{2}{ }^{-}, \alpha_{2}{ }^{+}$and $\alpha_{2}{ }^{-}$measures the long-run and short-run asymmetry, respectively by taking following hypotheses:

$$
\begin{gathered}
\mathrm{H}_{\mathrm{o}}: \beta_{2}{ }^{+}=\beta_{2}{ }^{-}=\mathrm{O} \\
H_{0}: \sum_{i=0}^{p 1} \alpha^{+}{ }_{2 i}=\sum_{i=0}^{p 2}{\alpha^{-}}_{2 i}
\end{gathered}
$$

for all $i=0, \ldots, p$. 


\subsection{Wavelet Multiscale Decomposition}

The second part of the methodology is Wavelet analysis. The Wavelet analysis is the time and frequency domain combination of any time series and decomposes it into different wavelet scales. It generates data decomposition in the orthogonal time scale and conserves the time data during frequency distribution (Ramsey, 1999). This method has ability to capture complete information in the time series related to location and time horizon (Gencay et al., 2002), and it deals with time series nonstationary properties (Mishra et al., 2019).

Any function of time can be expressed as the father $(\phi)$ and mother $(\psi)$ wavelets and integrate into one and represent very long scale smooth components of the signal and zero and are used to stand for deviations occurring in the smooth components, respectively (Ramsey, 2002). The scaling coefficient is given by father wavelets and generation of differencing coefficients through mother wavelets.

The representation of father wavelet and mother wavelet is as following:

$$
\begin{aligned}
& \phi_{j, k}=-2^{-j / 2} \phi\left(\frac{t-2^{j} k}{2^{j}}\right) \text { with } \int \phi(t) d t=1 \\
& \varphi_{j, k}=-2^{-j / 2} \varphi\left(\frac{t-2^{j} k}{2^{j}}\right) \text { with } \int \varphi(t) d t=1
\end{aligned}
$$

The basic function that is constituted by father and mother that describes the order of coefficients. The smooth and detail coefficients that are an offshoot from father and mother wavelets express as follows:

$$
\begin{aligned}
& S_{j, k}=\int f(t) \phi_{j, k} \\
& d_{j, k}=\int f(t) \varphi_{j, k} \text { withj }=1 \ldots j
\end{aligned}
$$

The multi-resolution breakdown of $f(t)$ expresses as $\left\{S_{j}, D_{j-1}, \ldots, D_{1}\right\}$ and $D_{j}$ measure the jth level wavelet details that is connected with series variation at scale $\lambda_{\mathrm{j}} \ldots . . S_{\mathrm{j}}$. That shows each level cumulative sum of alteration and $S_{j}$ becomes smooth and smoother as $j$ increase (Gencay et al., 2002). To estimate the scaling and wavelet coefficients, the study apply Maximal Overlap Discrete Wavelet Transform (MODWT) as it has novel property that not suffer any limitation like level of sample size is multiple of $2^{\mathrm{j}}{ }_{\mathrm{o}}$ as in Discrete Wavelet Transform (DWT) (Percival and Walden, 200o) and coefficients are more efficient over DWT (Percival, 1995; Gencay et al., 2002). The study decomposes the series D1 to D6 wavelet coefficients and the resolution of the data is given by detail coefficient $D_{j}$ at scale $2^{j}$ to $2^{j+1}$ and the $\mathrm{S}_{6}$ shows the movements in the long-run.

\subsection{Quantile-on-Quantile Regression (QQR)}

The existing literature showed initially linear methodology to check the two variable associations in time series data after then move to Quantile Regression developed by Koenker and Bassett's (1978), later becomes preferred econometric tool in time series data. Apart from the above, 
quantile regression is incapable of confining the entire dependency due to uncertain facts that may affect the association of the dependent and independent variables. Sim and Zhou (2015) developed the Quantile on Quantile (QQ) method that considers the lacuna of quantile regression. The essence of this method is that combine the two methods quantile regression and nonparametric estimations, which allow estimating the impact of a quantile variable over the other quantile variable (Mishra et al., 2019). The quantile methods have some advantages over linear methods like, (i) it provides outlier free, robust and efficient estimator; (ii) it is free from other issues heteroscedasticity and also reduces the multicollinearity by increasing the data availability; (ii) estimated parameters are more reliable because of the higher degree of freedom.

Basically, there are two approaches involves in quantile on quantile regression that are (i) triangular system of equation and (ii) single equation regression and that are introduced by Ma and Koenker (2006) and Sim and Zhou (2015), respectively. At this moment, the single equation regression approach applied for analysis, and it explained as to present our variables:

$$
F D_{t}=\beta^{\theta}\left(\operatorname{NRR}_{t}\right)+\mu t^{\theta}
$$

Where $F D_{t}$ indicates financial in a country in time t; $N R R_{t}$ denotes natural resource rents during this period. And the quantile error term, the conditional $\theta$ th quantile, is denoted by ut ${ }^{\Theta}$ which is equal to zero. Furthermore, $\beta^{\Theta}\left(\mathrm{NRR}_{\mathrm{t}}\right)$ that is unknown because of no prior information about the relationship.

Furthermore, for the determination of the relation between qth quantile of $F D$ and the tth quantile of natural resource rent denoted by $\mathrm{NRR}_{\mathrm{t}}$, in the neighbourhood of $\mathrm{NRR}_{\mathrm{t}}$, the logical, linear regression applied to equation (10). $\beta^{\theta}($.$) is known, and this function is solved through first-order$ Taylor expansion around a quantile $\mathrm{NRR}_{\mathrm{t}}$, as follows:

$$
\beta^{\theta}\left(N R R_{t}\right) \approx \beta^{\theta}\left(N R R^{T}\right)+\beta^{\theta^{\prime}}\left(N R R^{T}\right)\left(N R R_{t}-N R R^{T}\right)
$$

The above equation (11) presents the $\theta$ and $T$ both as double indexed which is the basic property of that equation, and $\beta^{\theta}\left(\mathrm{NRR}_{\mathrm{t}}\right)$ and $\beta^{\theta^{\prime}}\left(\mathrm{NRR}_{\mathrm{t}}\right)$ are revealed as parameters. Given that $\beta^{\theta}\left(\mathrm{NRR}_{\mathrm{t}}\right)$ and $\beta^{\theta^{\prime}}\left(\mathrm{NRR}_{\mathrm{t}}\right)$ is the function of $\mathrm{T}$, these are also the function of $\theta$ which are equal and function of both $\theta$ and $T \cdot \beta^{\theta}\left(\mathrm{NRR}_{\mathrm{t}}\right)$ and $\beta^{\theta^{\prime}}\left(\mathrm{NRR}_{\mathrm{t}}\right)$ can be reported as $\beta_{\mathrm{o}}(\theta, T)$ and $\beta_{1}(\theta, T)$ accordingly. The presentation of equation (11) as follows:

$$
\beta^{\theta}\left(N R R_{t}\right) \approx \beta_{0}(\theta, \tau)+\beta_{1}(\theta, \tau)\left(N R R_{t}-N R R^{T}\right)
$$

The equation (4) is obtained after the substitution of equation (12) is as follows:

$$
F D_{t}=\underbrace{\beta_{0}(\theta, \tau)+\beta_{1}(\theta, \tau)\left(N R R_{t}-N R R^{T}\right)}_{*}+u_{t}^{\theta}
$$

And this $\left(^{*}\right.$ ) in equation (13) refers to the $\mathrm{q}_{\text {th }}$ quantile of financial development.

Though, in converse to the standard conditional quantile function, this shows as mirrors the association between the $\theta$ th quantile of the financial development and the $t$ th quantile of natural resource rent. The change of quantile value of FD and NRR theses parameters also affected, and not 
support of linear link is considered between these variables. Therefore, the overall association between FD and NRR is expressed in equation (13) by their distribution. Through the solution of the below minimization problem gives the local linear regression estimates of the parameters $b o$ and $b 1$, that are the estimates of $\beta$ o and $\beta$ :

$\min _{b 0, b 2} \sum_{i=1}^{n} \rho^{\theta}\left[F D_{t}-b_{0}-b_{1} \overline{\left(\overline{N R R}_{t}\right.}-(\widehat{N R R})\right] \times K\left(\frac{F_{n(\overline{(\overline{N R R}})-T}}{h}\right)$

In Equation (14), the quantile loss functionis $\rho^{\theta}$, which is precise as $\rho^{\theta}(u)=u(\theta-I(u<0))$, and the common indicator function represented by I. $K(\cdot)$ express the kernel function and h shows the bandwidth. The Gaussian kernel method that is simple in computation and efficient is applied to weight the observations in the neighbour of $N R R \tau$. In this study, we use a bandwidth parameter $h=$ 0.05 by following Sim and Zhou (2015) and Shahzad et al. (2018).

\subsection{The Validity of Quantile-on-quantile Regression (QQR) Approach}

As stated earlier, the quantile-on-quantile estimation is analyzed to get and allocates the traditional quantile coefficients. It gives independent variable coefficients at different quantiles (Arain et al., 2019). In simple, the quantile regression created on $\sigma$ quantile of natural resource rent on financial development and this coefficient of quantile regression independently index by $\sigma$. On the other hand, the Quantile on quantile method takes $\pi$ th quantile effect of natural resource rent on $\sigma$ quantile of financial development (natural resource rent) at different values of $\sigma$ and $\pi$. That is why this approach provides a clear picture by its unique specification that connects the natural resource rent and financial development that linked to quantile regression.

\section{Results and Discussion}

\subsection{NARDL Results}

The prerequisite requirement for time series modelling is to check the order integration by using unit root tests. In the application of both ARDL and NARDL order of integration must be mixed or either level or first difference. No, any variable should be stationary at I(2). Our study used augmented DickyFuller (1979) and Phillips and Perron (1990) unit root test to check the order of integration. Table 1 presents the results that denote that all variables are stationary at first difference.

\section{Table 1 Unit Root Table}

\begin{tabular}{|l|l|l|l|l|l|l|}
\hline & & FD & NRR & GDP & GCF & INQ \\
\hline \multirow{2}{*}{ ADF Test } & At Level & -1.549 & -2.389 & 0.265 & 0.106 & -1.071 \\
\cline { 2 - 7 } & At First Difference & $-5.923^{* * *}$ & $-5.924^{* * *}$ & $-5.201^{* * *}$ & $-4.427^{* * *}$ & $-5.983^{* * *}$ \\
\hline \multirow{2}{*}{ PP Test } & At Level & -1.551 & -2.389 & 0.256 & -0.084 & -2.043 \\
\cline { 2 - 7 } & At First Difference & $-6.615^{* * *}$ & $-6.156^{* * *}$ & $-5.201^{* * *}$ & $-4.426^{* * *}$ & $-4.355^{* * *}$ \\
\hline
\end{tabular}

Note: ${ }^{* *}$ shows the significance level at $1 \%$.

The condition for long-run association exists if calculated F-stat will be greater than the upper bound. The bound test table 2 reports that there is no cointegration among variables in case ARDL model. Whereas the results of nonlinear ARDL model shows, cointegration exists among variables. 
Table 2 ARDL \& NARDL Bound Test

\begin{tabular}{|c|c|c|c|}
\hline & Lower Bound I(o) & Upper Bound I(1) & Decision \\
\hline $1 \%$ & 4.093 & 5.532 & \multirow[t]{3}{*}{ No Cointegration } \\
\hline $5 \%$ & 2.947 & 4.088 & \\
\hline $10 \%$ & 2.460 & 3.460 & \\
\hline F-Stat (ARDL) & \multicolumn{3}{|l|}{1.444} \\
\hline $1 \%$ & 3.900 & 5.419 & \multirow[t]{3}{*}{ Cointegration } \\
\hline $5 \%$ & 2.804 & 4.013 & \\
\hline $10 \%$ & 2.331 & $3 \cdot 417$ & \\
\hline F-Stat (NARDL) & 4.290 & & \\
\hline
\end{tabular}

Table 3 reports the results. The positive change in natural resource rent affects the financial development negatively that supports the resource curse hypothesis in long-run and short-run. Both findings reveal interesting findings and show asymmetry in the behaviour of natural resource rent with financial development. The results also show real GDP, gross capital formation and institutional quality affect financial development positively. The error correction mechanism provides the long-run equilibrium adjustment. Our result of ECT depicts significant with a negative sign that shows the surety of long-run equilibrium adjustment. Our results reveal that NARDL model passes all diagnostic tests that ensure the model is free from hetero, serial correlation, specification problem and normally distributed.

Table 3 NARDL Results

\begin{tabular}{|c|c|c|}
\hline Variables & Long Run Coefficients & Short Run Coefficient \\
\hline $\mathrm{NRR}^{+}$ & $\begin{array}{l}-0.18 * * * \\
{[0.06]}\end{array}$ & $\begin{array}{l}-0.17^{* * *} \\
{[0.05]}\end{array}$ \\
\hline $\mathrm{NRR}^{-}$ & $\begin{array}{l}-0.44^{* * *} \\
{[0.05]}\end{array}$ & $\begin{array}{l}-0.41^{* * *} \\
{[0.05]}\end{array}$ \\
\hline GDP & $\begin{array}{l}0.66 * * * \\
{[0.16]}\end{array}$ & $\begin{array}{l}0.62^{* * *} \\
{[0.14]}\end{array}$ \\
\hline $\mathrm{GCF}$ & $\begin{array}{l}0.21 * * * \\
{[0.06]}\end{array}$ & $\begin{array}{l}0.19^{* * *} \\
{[0.05]}\end{array}$ \\
\hline INQ & $\begin{array}{l}0.02^{* * *} \\
{[0.01]}\end{array}$ & $\begin{array}{l}0.03^{* * *} \\
{[0.01]}\end{array}$ \\
\hline $\mathrm{C}$ & $\begin{array}{l}16.09^{* * *} \\
{[3.46]}\end{array}$ & $\mathrm{R}^{2}: 0.91$ \\
\hline ECT(-1) & $\begin{array}{l}-0.93^{* * *} \\
{[0.11]}\end{array}$ & Adj. $R^{2}: 0.89$ \\
\hline LM Test & $1.24(0.30)$ & RESET: $0.04(0.84)$ \\
\hline BPG Test & $1.26(0.31)$ & J.B Test: $0.15(0.93)$ \\
\hline Asymmetry Test & $W_{L R}: 5.64(0.01)$ & $\mathrm{W}_{\mathrm{SR}}: 3.70(0.04)$ \\
\hline
\end{tabular}

Note:*** shows the significance level at $1 \%$ and values in () and [] represents p-value and standard deviation. 
The stability of the model is tested through CUSUM and CUSUMSQ test, and findings in Fig.1 presents that model is highly stable.
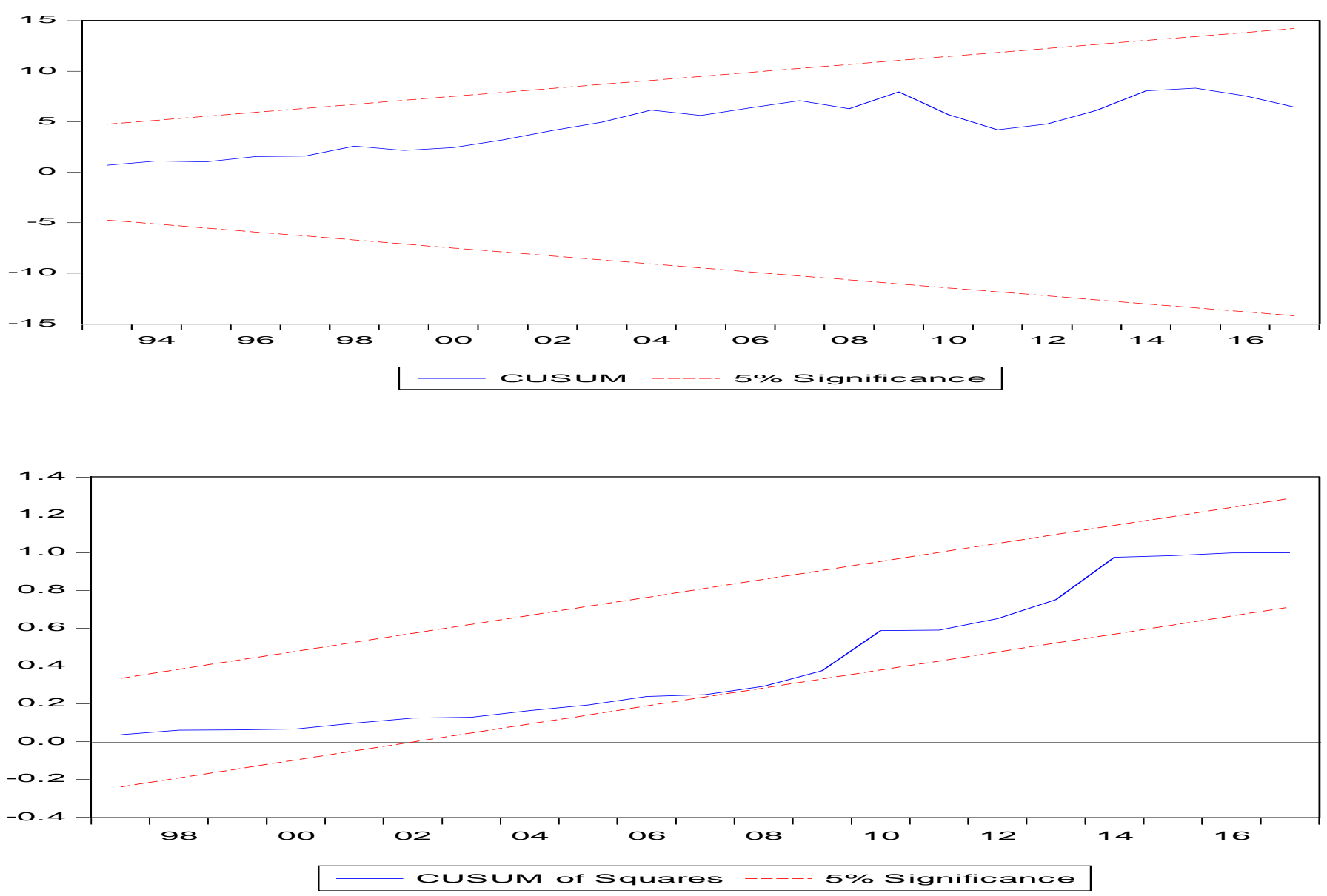

Fig. 1 CUSUM and CUSUMSQ

The asymmetries between NRR and FD are checked through the Wald test, and results in table 3 confirm the asymmetry. Graphically dynamic multiplier graph represents the asymmetric relation of natural resource rent with financial development, as shown below.

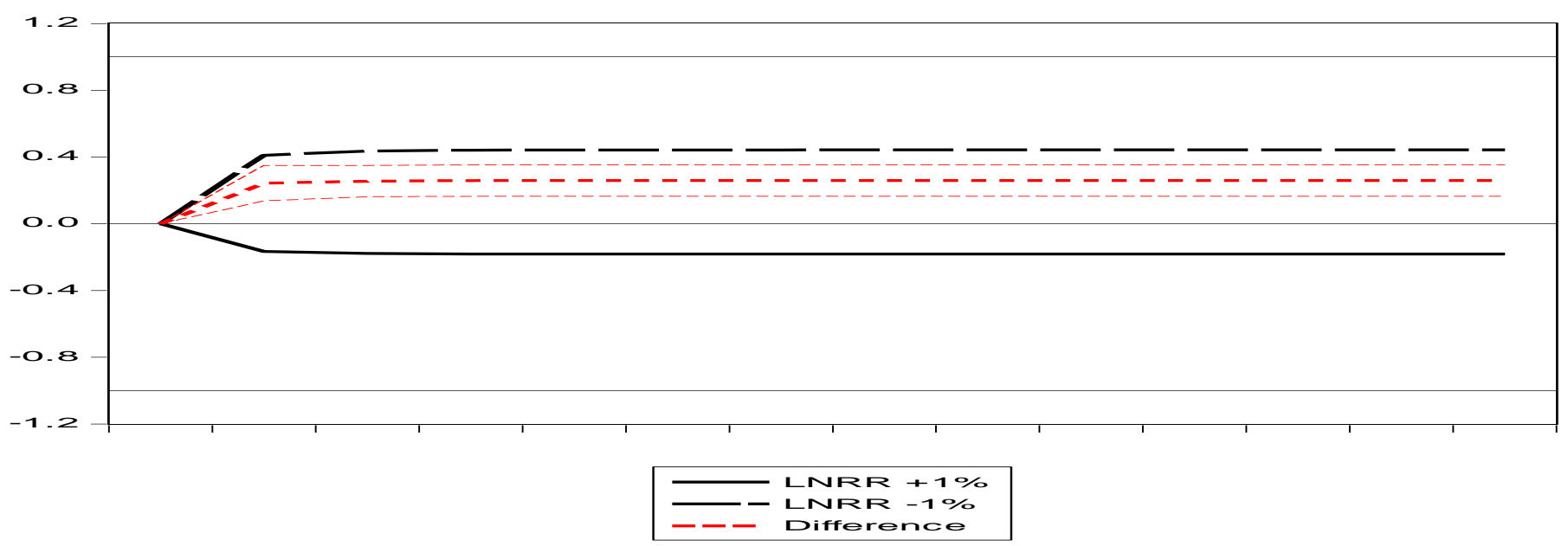

Fig. 2 Dynamic Multiplier Graph for NRR 


\subsection{Quantile-on-Quantile Approach Results}

The following figure 3 expresses the plot of estimates of QQ analysis and its different decomposed series of financial development and natural resource rent. The following figure 3 expresses the slope estimates $b_{1}(\sigma, \pi)$ that have $\pi$ th quantile effect of natural resource rent and its decomposed series on $\sigma$ th quantile of financial development.

The effect is positive of NRR and FD for groups of quantiles that suggest the direct relationship between these two variables. The significance is detected in the upper quantiles of NRR (i.e., 0.70-0.95) that linked to the upper quantiles of FD (i.e., 0.70-0.95) region. This positive impact is also detected in that region, which combines lower quantiles of both variables NRR and financial development. The influence of NRR on FD becomes weak in middle quantiles and becomes strong on lower to high quantiles of both variables. Findings show that these variables are strongly associated and are complements to each other for long run financial development in Saudi Arabia.

The next is to check the decomposed series influence NRR.d1 on financial development and found a significant effect of NRR.di on FD in the higher quantiles of NRR and lower quantiles of financial development. In the middle quantiles of both variables, the effect in different that is a lower effect. The effect is converging to negative on higher quantiles of both variables. Next, check the impact of second decomposed time series NRR.d2 on financial development that shows the positive effect on higher quantiles of NRR and lower quantiles of FD. But on lower quantiles of both NRR.d2 and FD, the effect becomes lower and converging to negative association. And in the middle quantiles of NRR.d2 and financial development, the positive impact is enormously weak. The influence of decomposed series NRR.d3 on financial development than found a weak effect at lower quantiles of both NRR.d3 and financial development. But on middle and higher quantiles, the effect remained significant.

Furthermore, the positive effect of NRR becomes weaker, and the negative effect is increased when we see the decomposed effect of NRR.d4 and NRR.d5 on financial development. This effect is either zero or becomes negative at the middle or lower quantiles of both variables. When we see more series of NRR.d6, then we find the same sign of decreasing the positive effect of NRR on FD. In the last, the scenario becomes change when we see NRR.d6s effect on financial development. In almost all regions find the influence of NRR on FD is negative. The above analysis concludes the effect of original time-series changes in NRR positively affected FD. But as we decomposed the series, the positive effect going to decrease becomes zero and then becomes negative with the stability of series increase.

\begin{tabular}{|l|l|l|}
\hline Natural Resource Rent Effect on Financial Development \\
\hline NRR & NRR.d1 \\
\hline
\end{tabular}




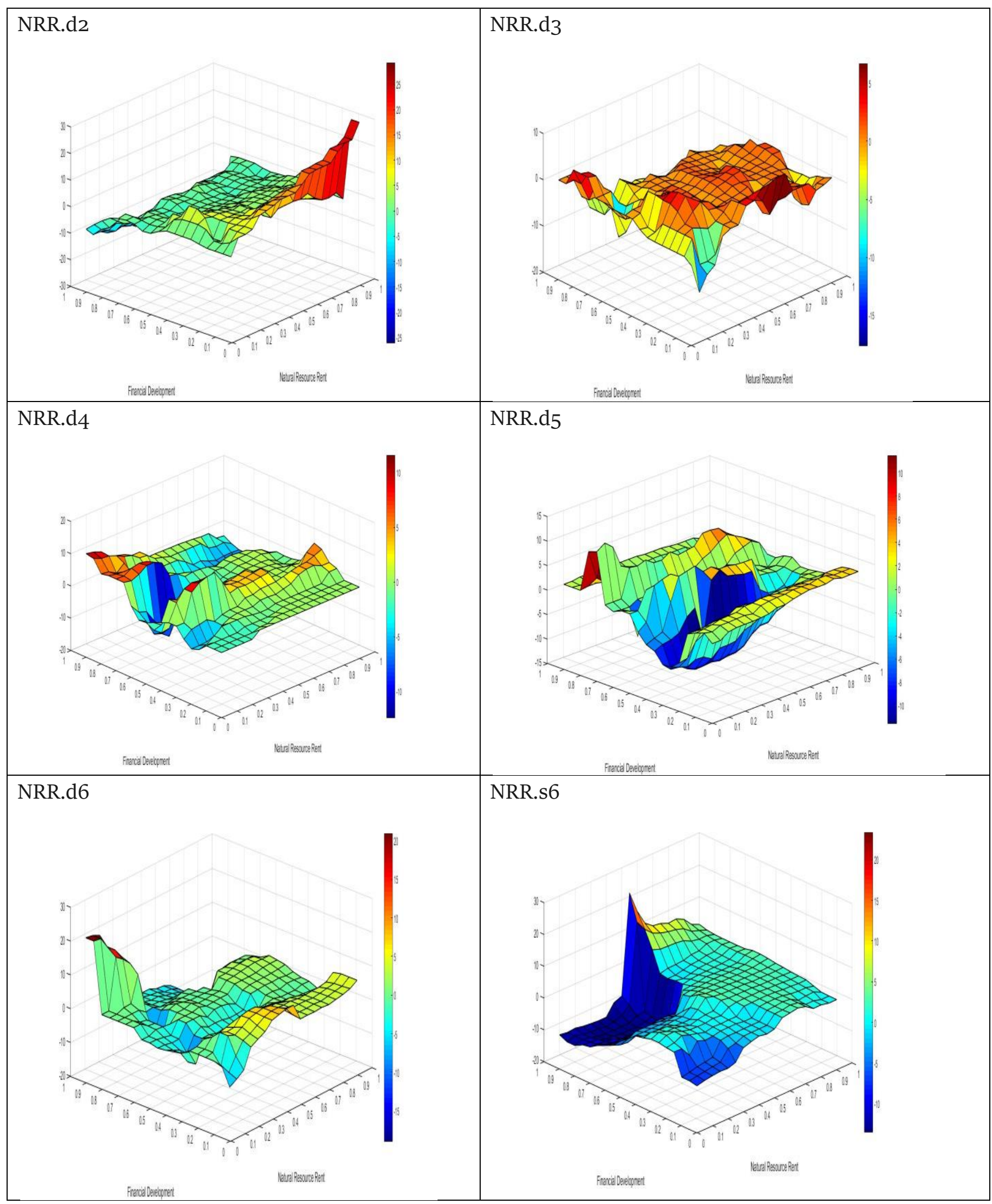

Fig. 3 The graphs demonstrate the slope coefficient estimates of $\beta 1$ on the $z$-axis and the quantiles of financial development on the $y$-axis and the quantiles of decomposing natural resource rent $\left(d_{1}, d_{2}, \ldots d_{6}\right.$ and $\mathrm{S}_{6}$ ) on the $\mathrm{x}$-axis. 


\subsection{The QQ method Validity}

The next step is to check the validity of and comparison of QR and QQR estimates. The following figure 4 shows the plot of the QR estimates and average of QQR estimates that show the effect of natural resource and its decomposes series on financial development. This plot shows the overall effect and decomposed time series influence of NRR that shows the variation and converging to a negative effect on FD. From the analysis, when natural resource rent decomposed time series, NRR.d1 then observed the effect on financial development becoming weak from positive to zero then negative across quantiles of both variables. The effect is similar when we check it with other decomposed time series NRR.d2, NRR.d4, NRR.d5, NRR.d6, and NRR.d6s.

Our results are similar to the studies of Sun et al. (2020) and Khan et al. (2020) that revealed the association of a natural resource with financial development and confirms negative association in emerging seven (E7) and China, respectively.

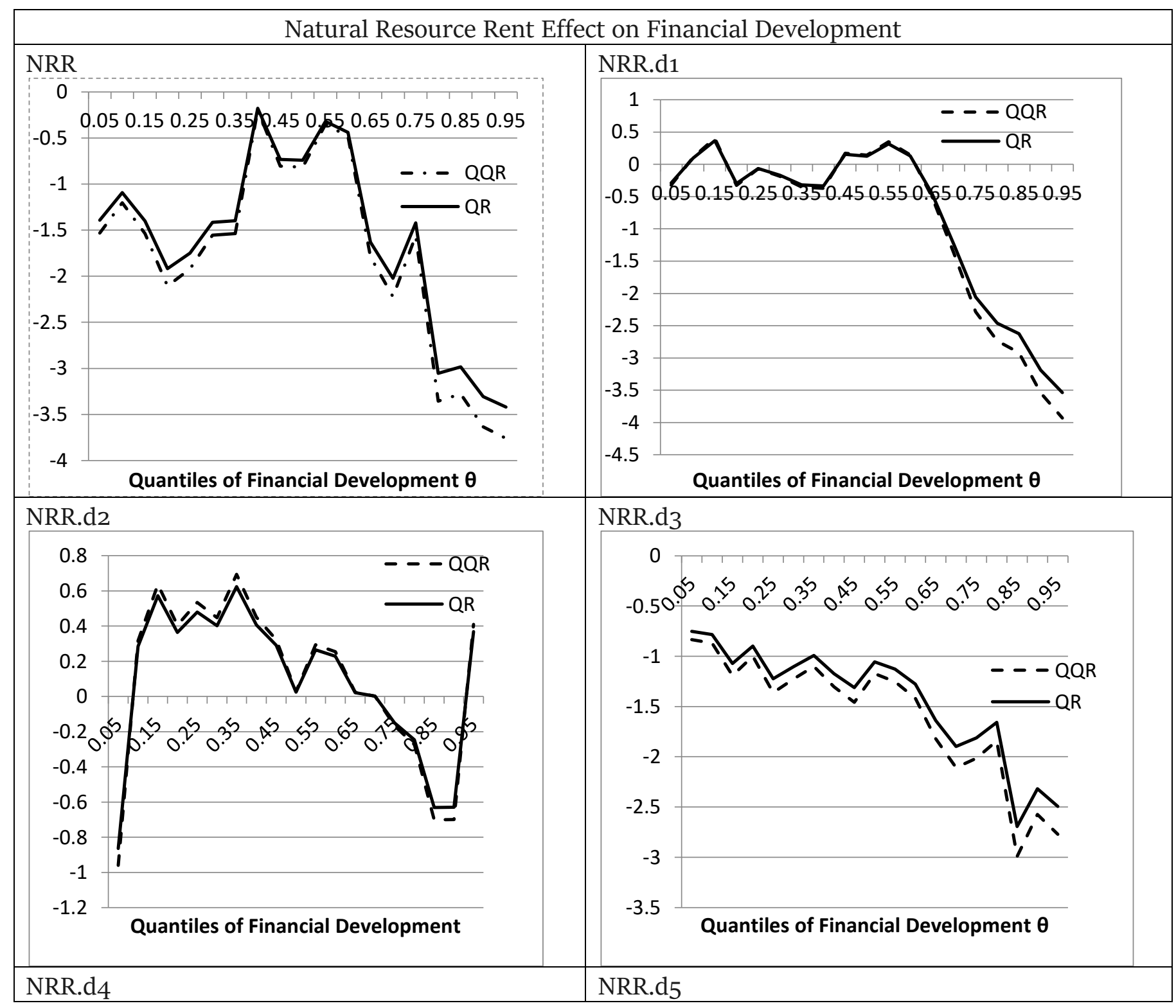


Review of Economics and Development Studies, Vol. 7 (1) 2021, 101-117

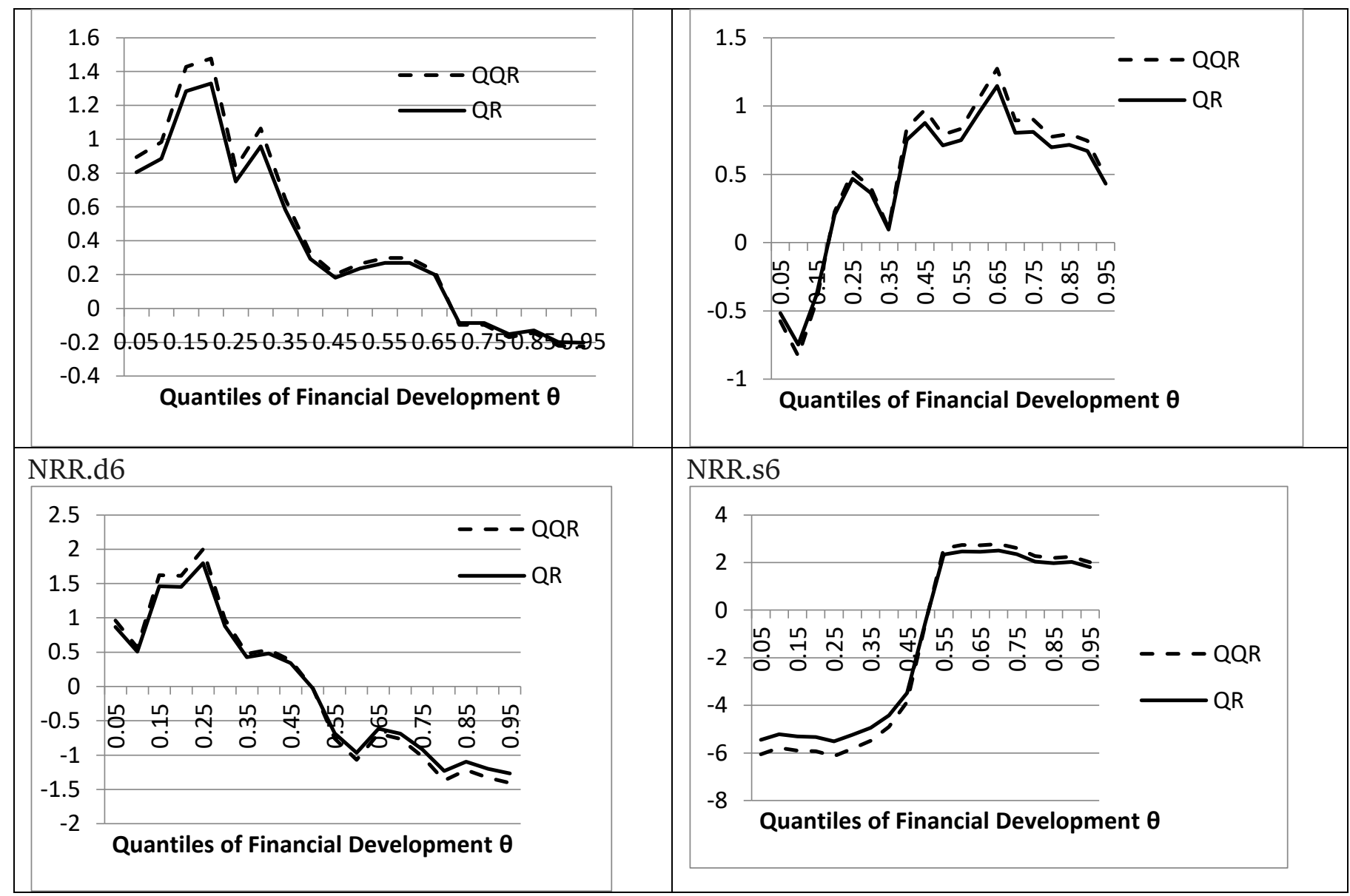

Fig. 4 Quantile Regression (QR) and QQR estimate comparison.

\section{Conclusion and Recommendations}

Our study analyzes the association of natural resource rent and financial development in Saudi Arabia by using quarterly data from 1985Q1 to 2017Q4. We employ two novel methodologies at the same time, such as nonlinear autoregressive model (NARDL) and Wavelet-based quantile-on-quantile estimation method to check the asymmetric behaviour of natural resource rent on financial development. The findings of NARDL confirm the nonlinear behaviour of NRR with FD. The results also show real GDP, gross capital formation and institutional quality affect FD positively. The study outcome of Wavelet-based quantile-on-quantile estimation method reveals the heterogeneous response of NRR effect on FD when decomposes into different quantiles that become positive to negative. However, our results are beneficial for policymakers and policy analysts because results are exciting that help them in conducting policy analyses.

Funding: No funding was received to conduct this research.

Contribution: All authors contributed equally.

Acknowledgment: We would like to acknowledge the contributions of research participants to this research paper.

Conflict of interest: On behalf of all authors, the corresponding author states that there is no conflict of interest associated with this manuscript. 


\section{References}

Al-Torkistani, H. M., Salisu, M. A., \& Maimany, K. A. (2016). Modeling a sustainable Saudi Arabian economy: the real issues. International Journal of Sustainable Development \& World Ecology, 23(2), 186-193.

Arain, H., Han, L., Sharif, A., \& Meo, M. S. (2019). Investigating the effect of inbound tourism on FDI: The importance of quantile estimations. Tourism Economics, 1354816619859695 .

Asif, M., Khan, K. B., Anser, M. K., Nassani, A. A., Abro, M. M. Q., \& Zaman, K. (2020). Dynamic interaction between financial development and natural resources: Evaluating the 'Resource curse'hypothesis. Resources Policy, 65, 101566.

Auty, R., \& Warhurst, A. (1993). Sustainable development in mineral exporting economies. Resources Policy, 19(1), 14-29.

Auty, R. M. (2001). The political economy of resource-driven growth. European economic review, 45(4-6), 839-846.

Bah, M. M., \& Saari, M. Y. (2020). Quantifying the impacts of energy price reform on living expenses in Saudi Arabia. Energy Policy, 139, 111352.

Balassa, B. A. (1980). The process of industrial development and alternative development strategies (Vol. $\quad 1$ ). Washington, DC: World Bank.

Bhattacharyya, S., \& Hodler, R. (2014). Do natural resource revenues hinder financial development? The role of political institutions. World Development, 57, 101-113.

Cheng, M., Chung, L., Tam, C. S., Yuen, R., Chan, S., \& Yu, I. W. (2012). Tracking the Hong Kong Economy. Occasional Paper, 3, 2012.

Corden, W. M., \& Neary, J. P. (1982). Booming sector and de-industrialisation in a small open economy. The economic journal, 92(368), 825-848.

Dickey, D. A., \& Fuller, W. A. (1979). Distribution of the estimators for autoregressive time series with a unit root. Journal of the American statistical association, 74(366a), 427- 431.

Dwumfour, R. A., \& Ntow-Gyamfi, M. (2018). Natural resources, financial development and institutional quality in Africa: Is there a resource curse?. Resources Policy, 59, 411426.

Elbadawi, I., \& Soto, R. (2016). Resource rents, political institutions and economic growth. Understanding and Avoiding the Oil Curse in Resource-Rich Arab Economies, 187-224.

Faheem, M., Mohamed, A., Farooq, F., \& Ali, S. (2019). Do Migrant Remittances Spur Financial Development in Pakistan? evidence From Linear and Nonlinear Ardl Approach. Review of Economics and Development Studies, 5(4), 869-880.

Gencay, R., Selcuk, Whitcher, B., 2002. An Introduction to Wavelets and Other Filtering Methods in Finance and Economics. Academic Press, San Diego, CA.

Guan, J., Kirikkaleli, D., Bibi, A., \& Zhang, W. (2020). Natural resources rents nexus with financial development in the presence of globalization: Is the "resource curse" exist or myth?. Resources Policy, 66, 101641.

Ghirmay, T. (2004). Financial development and economic growth in Sub-Saharan African countries: evidence from time series analysis. African Development

Review, 16(3), $\quad 415^{-} \quad 432$.

Hooshmand, M., SM, S. A. H., \& Rajabzadeh Moghani, N. (2013). Oil rents, institutions and financial development: Case study of selected oil exporting countries. Research 


\section{Review of Economics and Development Studies, Vol. 7 (1) 2021, 101-117}

Journal of Recent Sciences ISSN, 2277, 2502.

Islamic Financial Services Board. (2016). Islamic financial services industry stability report 2016. Retrieved from 20Stability\%2oReport\%202016\%20(final).pdf.

http://www.ifsb.org/docs/IFSI\%

Khan, Z., Hussain, M., Shahbaz, M., Yang, S., \& Jiao, Z. (2020). Natural resource abundance, technological innovation, and human capital nexus with financial development: a case study of China. Resources Policy, 65, 101585.

Koenker, R., Bassett, G., 1978. Regression quantiles. Econometrica 46 (1), 33-50.

Ma, L., \& Koenker, R. (2006). Quantile regression methods for recursive structural equation models. Journal of Econometrics, 134(2), 471-506.

Mishra, S., Sharif, A., Khuntia, S., Meo, S. A., \& Khan, S. A. R. (2019). Does oil prices impede Islamic stock indices? Fresh insights from wavelet-based quantile-on-quantile approach. Resources Policy, 62, 292-304.

Mlachila, M., \& Ouedraogo, R. (2019). Financial development curse in resource-rich countries: The role of commodity price shocks. The Quarterly Review of Economics and Finance.

Nawaz, K., Lahiani, A., \& Roubaud, D. (2019). Natural resources as blessings and financegrowth nexus: A bootstrap ARDL approach in an emerging economy. Resources Policy, 6o, 277-287.

Niknamian, S. (2019). Resource-economic growth nexus, role of governance, financial development, globalisation and war: dynamic approach. Financial Development, Globalisation and War: Dynamic Approach (January 1, 2019).

Omri, A., Daly, S., Rault, C., \& Chaibi, A. (2015). Financial development, environmental quality, trade and economic growth: What causes what in MENA countries. Energy Economics, 48, 242-252.

Percival, D. P. (1995). On estimation of the wavelet variance. Biometrika, 82(3), 619-631.

Percival, D.B., Walden, A.T., 200o. Wavelet Methods for Time Series Analysis. Cambridge University Press, Cambridge, UK.

Perron P (1990) Testing for a unit root in a time series with a changing mean. J Bus Econ Stat $8(2): 153-162$

Rajan, R. G., \& Zingales, L. (2003). The great reversals: the politics of financial development in the twentieth century. Journal of financial economics, 69(1), 5-50.

Ramsey, J. B. (1999). The contribution of wavelets to the analysis of economic and financial data. Philosophical Transactions of the Royal Society of London. Series A: Mathematical, Physical and Engineering Sciences, 357(1760), 2593-2606.

Ramsey, J.B., 2002. Wavelets in economics and finance: past and future. Stud. Nonlinear Dynam. Econom. 6 (3), 1- 29.

Sachs, J. D., \& Warner, A. M. (1995). Natural resource abundance and economic growth (No. w5398). National Bureau of Economic Research.

Sachs, J. D., \& Warner, A. M. (2001). The curse of natural resources. European economic review, 45(4-6), 827-838.

SAMA, 2018. Yearly Statistics 2018. Saudi Arabian Monetary Authority, Saudi Arabia.

Samargandi, N., Fidrmuc, J., \& Ghosh, S. (2014). Financial development and economic growth in

an oil-rich economy: The case of Saudi Arabia. Economic Modelling, 43, 267-278.

Shahbaz, M., Naeem, M., Ahad, M., \& Tahir, I. (2018). Is natural resource abundance a stimulus for financial development in the USA?. Resources Policy, 55, 223-232.

Shahbaz, M., Zakaria, M., Shahzad, S. J. H., \& Mahalik, M. K. (2018). The energy consumption and economic growth nexus in top ten energy-consuming countries: Fresh 
Review of Economics and Development Studies, Vol. 7 (1) 2021, 101-117

evidence from using the quantile-on- quantile approach. Energy Economics, 71, 282-301.

Shahbaz, M., Destek, M. A., Okumus, I., \& Sinha, A. (2019). An empirical note on comparison between resource abundance and resource dependence in resource abundant countries. Resources Policy, 60, 47-55.

Shin, Y., Yu, B., \& Greenwood-Nimmo, M. (2014). Modelling asymmetric cointegration and dynamic multipliers in a nonlinear ARDL framework. In Festschrift in honor of Peter Schmidt (pp. 281-314). Springer, New York, NY.

Sim, N., \& Zhou, H. (2015). Oil prices, US stock return, and the dependence between their quantiles. Journal of Banking \& Finance, 55, 1-8.

Song, C. Q., Chang, C. P., \& Gong, Q. (2020). Economic growth, corruption, and financial development: Global evidence. Economic Modelling.

Sun, Y., Ak, A., Serener, B., \& Xiong, D. (2020). Natural resource abundance and financial development: A case study of emerging seven (E- 7) economies. Resources Policy, 67, 101660.

Van der Ploeg, R., \& Venables, T. (2009). Symposium on resource rich economies Introduction. Oxford Economic Papers, 61(4), 625-627.

Yuxiang, K., \& Chen, Z. (2011). Resource abundance and financial development: Evidence from China. Resources Policy, 36(1), 72-79.

Zaidi, S. A. H., Wei, Z., Gedikli, A., Zafar, M. W., Hou, F., \& Iftikhar, Y. (2019). The impact of globalization, natural resources abundance, and human capital on financial development: $\quad$ Evidence from thirty-one OECD countries. Resources Policy, 64, 101476.

Zhang, Q., \& Brouwer, R. (2020). Is China affected by the resource curse? A critical review of the Chinese literature. Journal of Policy Modeling, 42(1), 133-152.

Zoega, G., Gylfason, T., 2001. Natural Resources And Economic Growth: the Role Of Investment (No. 2743). CEPR Discussion Paper. 